\title{
Obituary: Alfred Leo Maria Fettweis (1926-2015)
}

\author{
Sankar Basu ${ }^{1}$. Anton Kummert ${ }^{2}$. \\ Klaus Meerkoetter ${ }^{3}$
}

CC Springer Science+Business Media New York 2015

Alfred Fettweis, a giant in the fields "circuits and systems" and "multidimensional systems theory", passed away on August 20, 2015 in Bochum, Germany.

Our community has lost a pioneer in the field who always had been closely connected to our journal "Multidimensional Systems and Signal Processing", for which he served as a founding board member from 1990 to 1993. It is only a sad coincidence that the sequence of his many personal contributions to MSSP will end with a joint paper together with one of us in this issue. Alfred Fettweis had close scientific cooperation and many exchange of ideas with Nirmal K. Bose, the founding editor of this journal, and his advice with respect to the evolution of MSSP had been always appreciated.

Born on November 27, 1926 in Eupen, Belgium, Alfred Fettweis received the degrees of Ingénieur Civil Electricien and Docteur en Sciences Appliquées from Catholic University of Louvain, Belgium, in 1951 and 1963, respectively. During the time between 1951 and 1963 he was employed as an engineer at the International Telephone and Telegraph Corporation (ITT) in Belgium and in the USA (1954-1956) — an experience from which he accrued valuable practical skill and experience. This phase of his professional life in an industrial environment strongly influenced his later career as a scientist. He always emphasized that scientific results, including even theoretical ones, should have a practical impact.

Sankar Basu

sabasu@nsf.gov

Anton Kummert

kummert@uni-wuppertal.de

Klaus Meerkoetter

meerkoetter@nachrichtentheorie.de

1 Division of Computing and Communications Foundations, National Science Foundation, Arlington, VA 22230, USA

2 Faculty of Electrical, Information and Media Engineering, University of Wuppertal, Rainer-Gruenter-Strasse 21, 42119 Wuppertal, Germany

3 Universität Paderborn, 33098 Paderborn, Germany 
From 1963 to 1967, he was a Professor at Eindhoven University of Technology, The Netherlands. Since 1967, he has been a Professor (emeritus professor since 1992) at Ruhr-Universitaet Bochum, Germany, where he held the Chair for Nachrichtentechnik (communication theory). From 1994 till 1996 he was a Distinguished Professor of Computer Science and Engineering at the University of Notre Dame, USA.

His outstanding scientific achievements have been awarded by honorary doctorates from six different universities: in 1986, Teknologie Doktor h.c., Linkoping, Sweden, in 1988, Docteur Honoris Causa, Faculté Polytechnique de Mons, Mons, Belgium and Doctor Honoris Causa, Catholic University of Louvain, Belgium, in 1995, Doctor Honoris Causa, Technical University Budapest, Hungary, in 2004, Doctor Honoris Causa, Technical University of Poznan, Poland, in 2011, Doktor der Ingenieurwissenschaften Ehren halber, University of Paderborn, Germany.

The IEEE circuits and systems society (CASS) has been influenced deeply by Alfred Fettweis. A life Fellow of IEEE, his IEEE activities included Vice President Region 8 (1987) of CASS, Member of CASS ADCOM (1973-1975) and the Board of Governors (1995-1997), Technical Program Chairman of ISCAS - 76, and Co-Guest-Editor (1978) and Overseas Associate Editor (1977-1979) of the IEEE Transactions on Circuits and Systems.

Besides IEEE, he had been a member of several German and European academies and professional societies, including North Rhine-Westphalian Academy of Sciences and Arts, Germany, Academia Europaea, London, Academia Scientiarum et Artium Europaea, Salzburg/Vienna, and acatech (German Academy of Technical Sciences).

He enjoyed the highest international reputation, and the scientific societies bestowed upon him numerous prestigious awards, including Darlington Prize Paper Award of IEEE CASS in 1981, VDE-Ehrenring in 1984, Technical Achievement Award of IEEE CASS, Karl Kuepfmueller-Prize of ITG in 1988, Van Valkenburg Award of IEEE CASS in 2001, Vitold Belevitch Award of IEEE CASS in 2003, Gustav Robert Kirchhoff Award of IEEE in 2008, and the IEEE Centennial Medal.

During his long professional life, Alfred Fettweis made outstanding contributions to engineering as well as physics. He is, according to many, one of the fathers of digital signal processing and most definitely the inventor of passivity based digital systems called wave digital filters (WDF). Since passivity is a basic physical phenomenon it is not astonishing that this principle also had been adopted by him for modeling of multidimensional systems by using multidimensional Kirchhoff circuits. The latter can be transformed to discrete (digital) multidimensional filters by generalizing the classical $1 \mathrm{D}$ techniques in a nontrivial manner. Even nonlinear physical systems appearing, e.g., in fluid dynamics, have been modelled successfully by him in this way.

Today, we are living in a digital world of smart phones, tablet PCs, compressed video and audio files that are devices and techniques which appear to be an afterthought for the younger generation. All of these developments are based on advances in digital signal processing going back at least 50 years ago, in which the first steps had indeed been deeply influenced by Alfred Fettweis. In view of the current importance of such achievements, some anecdotes from the early days seem amusing. Alfred Fettweis' first pioneering paper on wave digital filters had been rejected by IEEE with the remark that the practical relevance of his invention could not be seen. Similarly, he often said with a smile on his face that the chief engineer of a big international company once told him: "Dear Prof. Fettweis, you are doing quite nice things, however, I forecast that digital signal processing never will gain any practical relevance in technical systems. Everything is better and cheaper done by analog systems."

After his retirement Alfred Fettweis shifted the focus of his research to foundational aspects of physics including considerations of special theory of relativity and the nature of 
electrons. He had been convinced that Kirchhoff theory together with the concepts of passivity and losslessness, can also be the key for the understanding of such physical phenomena. It is a genuine loss that he did not have the time to finalize his research this field.

We received many notes of condolence on the loss of Alfred Fettweis from all over the world. Citing some of them gives the liveliest and best impressions: "He was one of the real giants of Circuits Theory." "He was very kind, motivating and generous towards everyone regardless whether they are colleagues, friends or students." He will never be forgotten." "I was considering Professor Alfred Fettweis as an academic father in the sense that his academic ethics, integrity, kindness, modesty, his spirit of meritocracy and his dedication to quality research ...guided my path,...". "He was a man of great character, humble; pleasant to deal and work with."

His dedication to our "multidimensional" community will be missed by all who knew him well. He is survived by his wife, 5 children and 16 grandchildren. 